\title{
AUTOMATING FORWARD AND REVERSE SUPPLY CHAINS IN THE CONTEXT OF INDUSTRY 4.0
}

\author{
Florina Livia COVACI* \\ Babeș-Bolyai University, Romania
}

\begin{abstract}
The $4^{\text {th }}$ industrial revolution brings in a transformation of the traditional supply chain towards a digital supply chain. The machines will be able to use algorithms that will enable them to automate the supply chain formation process and to quickly react to disruptions. The current approach proposes a mechanism based on a message passing inference scheme in order to address the automated supply chain formation problem in a closed-loop supply chain by integrating forward and reverse supply chains. Forward supply chain imply a series of activities required to produce new products from virgin materials and distribute them to consumers while reverse supply chains require collecting used products from consumers and reprocessing them to either recover their leftover market values or dispose of them. It has become common for companies involved in a forward supply chain to also carry out collection and reprocessing of used products. Strict environmental regulations and diminishing raw material resources have intensified the importance of reverse supply chains at an increasing rate. The proposed mechanism is evaluated using two type of supply chain configurations from textile and automobile industry, demonstrating that automated integration of reverse supply chains along with forward supply chains, lead to benefits for the participants in the supply chain.
\end{abstract}

JEL classification: C61

Keywords: Forward Supply Chain, Reverse Supply Chain, Closed-Loop, Automated Supply Chain Formation, Belief Propagation

\section{Introduction}

The closed-loop represents an important topic within the domain of supply chain (SC) formation in the recent times. A closed-loop supply chain implies combining the forward supply chain with reverse SC, maintaining and recovering value from used products, while helping to create as little waste as possible (Govindan et al., 2015).

Due to environmental regulations or consumer pressures, the companies are being constrained to set up reverse supply chains (Patroklos, Besoiu, 2010).

\footnotetext{
* Corresponding author. Address: Faculty of Economics and Business Administration, BabeșBolyai University, Romania, Teodor Mihali str 58-60, Email: florina.covaci@ubbcluj.ro
} 
For instance, the Waste Electrical and Electronic Equipment (WEEE) directive (directive 2002/96/EC) became European law in 2003, which contains mandatory requirements on collection, recycling, and recovery for all types of electrical goods, with a minimum rate of 4 kilograms per head of population per annum (Patroklos, Besoiu, 2010). WEEE-like legislation was also introduced in Canada, Japan, China, and many states in the US (Quariguasi Frota Neto, et al., 2010).

In a forward supply chain, the customer is typically the final entity of the process. However, a closed-loop supply chain includes the returns processes, the reverse supply chains being now a revenue opportunity for manufacturers instead of a cost-minimization approach (Guide, Van Wassenhove, 2009). Industry 4.0 transformations will enable machines to make autonomous decisions, hence there is need to create algorithms that will enable the shift from traditional supply chains to the digital supply chains of the future by automating several process.

Several studies have been conducted regarding automation of the Forward Supply Chain Formation (SCF). The work of Cerquides et al. (2007), Collins et al. (2002) and Walsh et al. (2000) addressed the problem by means of combinatorial auctions that compute the optimal SC allocation in a centralized manner. Recent papers that consider the SCF problem are using a message passing mechanism in graphical models in order to solve the SCF problem. In Winsper and Chli (2010, 2012, 2013), a decentralized and distributed approximate inference scheme, named Loopy Belief Propagation (LBP) was applied to the SCF problem, noting that the passing of messages is comparable to the placing of bids in standard auctionbased approaches. The authors show that the SCF problem can be cast as an optimization problem that can be efficiently approximated using max-sum algorithm (Bishop, 2006). Thus, the authors offer the means of converting a SCF problem into a local term graph, on which max-sum can operate. As LBP suffers of scalability issues in Penya-Alba et al. (2012) the authors introduce the Reduced Binarized Loopy Belief Propagation algorithm (RB-LBP). RB-LBP is based on the max-sum algorithm and introduces binary variables in order to encode decoupled buy and sell decisions and a selection term and an equality term in order to assure coherent decisions between participants.

However, the existing research literature for automation of the supply chain formation does not consider automating also the reverse supply chains as a closed-loop.

Hence the current work proposes a mechanism for automating the closedloop supply chain and also evaluates the impact of integrating reverse supply chains along with forward supply chains.

The paper is structured as follows: the first section provides an introduction of the considered problem, section 2 provides the fundamentals of the concept of Industry 4.0 , section 3 describes the terms of forward and reverse supply chain and emphasizes the differences between them, section 4 highlights the challenges for reverse supply chain, section 5 provides the description of existing work regarding automated supply chain formation, section 6 describes our proposed mechanism for automated closed-loop formation, section 7 provides implementation details and evaluation and finally section 8 provides conclusions and future work. 


\section{Fundamentals of Industry 4.0}

Industry 4.0 specifically involves a radical change in how production process currently operate. Defined by many as a global transformation of the manufacturing industry by the introduction of digitalization and the Internet, these transformations consider revolutionary improvements in the design and manufacturing processes, operations and services of manufacturing products and systems. The notion of Industry 4.0 has been labeled in different ways as: Smart Industry, Smart Factories, Advanced Manufacturing or Industrial Internet of Things (IloT). A smart factory is referred to as the use of new innovative developments in digital technology including "advanced robotics and artificial intelligence, hi-tech sensors, cloud computing, the Internet of Things, data capture and analytics, digital fabrication (including 3D printing), software-as-a-service and other new marketing models, mobile devices, platforms that use algorithms to direct motor vehicles (including navigation tools, ride-sharing apps, delivery and ride services, and autonomous vehicles), and the embedding of all these elements in an interoperable global value chain, shared by many companies from many countries" (Geissbauer et al., 2016). Within the context of Industry 4.0, the factory of the future will enable the connection between machines and human-beings in Cyber-Physical-Systems (CPSs). These new systems focus their resources on the introduction of intelligent products and industrial processes that will allow the industry to face rapid changes in shopping patterns (Brettel et al., 2014). Generally speaking, the term Industry 4.0 involves four main features (Hahn, 2014):

Horizontal integration via a new generation of global value chain networks: The implementation of the CPS within the smart factory requires strategies, networks and business models to accomplish a horizontal integration, which subsequently provides high levels of flexibility, enabling the company to respond faster. The transparency within the value chain allows the manufacturer to identify changes in customer requirements and to reflect them in all of the production steps, from development to distribution.

Vertical networking of smart production systems: This type of networking is based on CPSs to build reconfigurable factories that are flexible and react rapidly to changes in the customer demand. Manufacturing processes in a smart factory enable the true mass customization. It enables not only autonomous organization of production management but also maintenance management. Resources and products are networked, and materials and parts can be located anywhere and at any time. All processing stages in the production process are logged, with discrepancies registered automatically.

Through-life engineering support across the entire value chain: Innovation and technical improvements in engineering are present in the design, development and manufacturing processes. These enable the creation of new products and production systems utilizing a large amount of information (big-data).

Acceleration through exponential technologies: The implementation of innovative technologies enables companies to reduce costs, increase flexibility and customize the product. Industry 4.0 involves automated systems including Artificial Intelligence (Al), robots, drones, nanotechnologies and a variety of inputs that enable customization, flexibility and rapid manufacturing. 
Industry 4.0 also promotes the use of big data, loT and Artificial Intelligence (Al) as one. This revolution envisages an environment whereby smart machines can communicate with one another, not only to enable the automation of production lines but also to analyze and understand a certain level of production issues and, with minimal human involvement, to solve them. Even though this revolution is initially considered to affect mostly manufacturing industries, these innovations will affect retailers, operations companies as well as service providers.

\section{Forward and Reverse Supply Chains}

The forward supply chain (FSC) includes of series of activities in the process of converting raw materials to finished products. The managers try to improve forward supply chain performances in areas such as demand management, procurement, and order fulfillment (Cooper et al., 1997).

Reverse supply chain (RSC) is defined as the activities of the collection and recovery of product returns in supply chain management (SCM). Economic features, government directions, and customer pressure are three aspects of reverse logistics (Melo, et al., 2009). Generally, there are more supply points than demand points in reverse logistics networks when they are compared with forward networks (Snyder, 2006). Reverse logistics include the process of planning, implementing and controlling the inbound flow and storage of secondary goods and related information opposite to the traditional supply chain directions for the purpose of recovering value and proper disposal (Fleischmann, 2001).

The reverse supply chain, starts from end producers where used products are collected from customers (return products) and then attempts to manage end of life (EOL) products through different decisions are undertaken including recycling (to have more raw materials or raw parts), remanufacturing (to resale them to first customers) and finally, disposing of some used parts. Table 1 presents difference in forward and reverse supply chains.

For instance, the discarded plastic polyethylene terephthalate (PET) bottles are collected from the market, then are either remanufactured or used as regrind mixed with virgin PET to produce new bottles to satisfy varying demand. Kodak remanufactures its single-use cameras after the film has been developed. H\&M collects unwanted clothes, placing easily accessible collection boxes in almost all $\mathrm{H} \& \mathrm{M}$ stores, rewarding contributors with discounts as thanks. All collected clothes are then recycled into the first new yarn to make new clothes and then they are blended in about $20 \%$ of these fibers without any loss of quality or longevity. Within the automobile industry companies like Bosch, Volvo and General Motors are the few ones to name which have successfully implemented the reverse logistics in their supply chain management.

If we consider the forward and reverse supply chains simultaneously, the result network will construct a closed-loop supply chain. In general, the companies that have been most successful with their reverse supply chains are those that closely coordinate them with their forward supply chains, within a closed-loop system. For example, they make product design and manufacturing decisions with eventual recycling and reconditioning in mind. 
Table 1 Differences in forward and reverse supply chains

\begin{tabular}{|l|l|}
\hline Forward & Reverse \\
\hline Forecasting relatively straightforward & Forecasting more difficult \\
\hline One to many transportation & Many to one transportation \\
\hline Product quality uniform & Product quality not uniform \\
\hline Destination/routing clear & Product packaging often damaged \\
\hline Standardized channel & Destination/routing unclear \\
\hline Disposition options & Exception driven \\
\hline Pricing relatively uniform & Disposition not clear \\
\hline Importance of speed recognized & Pricing dependent on many factors \\
\hline $\begin{array}{l}\text { Forward distribution costs closely monitored } \\
\text { by accounting systems }\end{array}$ & Speed often not considered a priority \\
\hline Inventory management consistent & Reverse costs less directly visible \\
\hline Product lifecycle manageable & Inventory management not consistent \\
\hline Negotiation between parties straightforward & Product lifecycle issues more complex \\
\hline Marketing methods well-known & $\begin{array}{l}\text { Negotiation complicated by additional } \\
\text { considerations }\end{array}$ \\
\hline $\begin{array}{l}\text { Real-time information readily available to } \\
\text { track product }\end{array}$ & Marketing complicated by several factors \\
\hline
\end{tabular}

Source: Tibben-Lembke and Rogers, 2002

There are multiple reasons for implementing or operating through the reverse logistics systems. The economic, legal, and social reasons are among the few important ones to name. The economic reasons are the direct reasons behind the popularity of reverse logistics. Reverse logistics essentially helps in reduction of disposal costs and the usage of raw materials. Also, any indulgence in the reverse logistics essentially depict the significance of environmentally responsible behavior for the ensuring the improvements in customer relations (Ravi, Shankar, 2012), (Khan et al., 2016). There are also several legal bindings for being indulged in the reverse logistics. For instance, the companies in European Union are required to ensure the most appropriate disposal or recovery of waste that is a result of their production activities. According to Grabara et al. (2014) and Rubio and Parra (2014) there are also social reasons behind the increasing attention paid to reverse logistics. There is an ever increasing awareness in the society for protecting the environment and capitalizing over the scarce resources. Thus, reverse logistics facilitate the companies to be environment friendly as carbon emission and waste generation is immensely reduced.

\section{Challenges for Reverse Logistics}

There are different challenges which underline the implementation of reverse logistics in the supply chain management of companies. According to Demirel et al. (2014) and Khan et al. (2017) there are the challenges due to which companies hesitate to become involved in the process of reverse logistics. Below are highlighted the most important challenges for the implementation of reverse logistics in the supply chain management of companies. 
Willingness to Pay: One of the most important challenges that highlight the utilization of reverse logistics is the minimum willingness to pay for the products. There is a general assumption amongst consumers that remanufactured products are not as effective and useful as the newly made products are. This assumption directly impacts the willingness to pay for the remanufactured products. Consumers essentially believe that the remanufactured products have a lower value than the original products (Chan et al., 2012). Consumers are not at all willing to pay any premium prices for such products as compared to the genuine products. This is one of the most important challenges that force the organizations not to be involved in the reverse logistics process. Consumers urge that companies must clearly state that the products are remanufactured.

Consumers' Perception: Another important challenge that entails the domain of reverse logistics is related to the consumers' perceptions. Consumers do not buy products without the satisfaction of the product's quality. If the remanufactured products are priced low, consumers would believe that the quality is low and thus only few consumers would pay for such products (Ravi, Shankar, 2012).

Cannibalization: Remanufacturing of old products may cannibalize the sales of new products, if the customers are convinced to purchase the remanufactured products. This might lead to a situation where companies are not able to sell their new products. However, the underlying benefits associated with the remanufacturing can easily outcast the costs of cannibalization (Aitken, Harrison, 2013).

\section{Background for Automating Supply Chains}

The Supply Chain Formation (SCF) problem has been widely studied by the multi-agent systems community using computational agents that act in behalf of the participants during the SCF process and making possible to form SCs in a fraction of the time required by the manual approach (Walsh et al., 2000, Collins et al., 2002, Walsh, Wellman, 2003, Cerquides et al., 2007, Giovannucci et al., 2008, Winsper, Chli, 2010, Mikhaylov et al., 2011, Winsper, Chli, 2012, Winsper, Chli, 2013).

The SCF methods can be classified in three categories depending on the architecture they follow. A first division is to separate SCF into centralized and decentralized architectures. Furthermore, we can separate the decentralized methods into two further categories depending on whether the communication between participants is either direct or mediated.

In a centralized approach (Walsh et al., 2000, Collins et al., 2002, Cerquides et al., 2007, Giovannucci et al., 2008, Mikhaylov et al., 2011), participant agents inform a central authority of their preferences (encoded as offers). After collecting the offers of all participant agents, the central authority determines the resulting SC.

Decentralized SCF appears as an alternative to centralized SCF in order to overcome some of its limitations as: participants might be reluctant to share this information with any central authority, given the hardness of the SCF problem centralized optimal solvers might suffer from scalability issues, the existence of a central authority introduces a single point of failure for the SCF process.

One approach to decentralized SCF is that of mediated SCF. In this setting, participant agents resort to local markets in which the goods they want to sell or buy are being traded (Walsh et al., 2000, Walsh, Wellman, 2003). The authors proposed a market protocol with bidding restrictions referred to as simultaneous 
ascending $(\mathrm{M}+1)$ st price with simple bidding (SAMP-SB), which uses a series of simultaneous ascending double auctions. SAMP-SB was shown to be capable of producing highly-valued allocations solutions which maximize the difference between the costs of participating producers and the values obtained by participating consumers over several network structures, although it frequently struggled on networks where competitive equilibrium did not exist. The authors also proposed a similar protocol, SAMP-SB-D, with the provision for de-commitment in order to remedy the inefficiencies caused by solutions in which one or more producers acquire an incomplete set of complementary input goods and are unable to produce their output good, leading to negative utility.

Another approach to decentralized SCF is Peer-to-Peer (P2P), where each participant agent communicates directly with the participant agents representing its potential buyers and sellers (Winsper, Chli, 2010), (Penya-Alba, 2012). Therefore, the SCF process takes place between participant agents with no intervention of any third party, thus preserving participants' privacy since they only need to share their preferences with local trusted parties rather than communicating them to a central authority and it offers better scalability for large scenarios due to the fact that each participant is responsible of a small part of the computation.

Loopy Belief Propagation (LBP) is the first peer to peer approach that has been used to solve the SCF problem in a decentralized manner (Winsper, Chli, 2010, 2012, 2013). The work in Winsper and Chli (2013) shows that the SCF problem can be cast as an optimization problem that can be efficiently approximated using max-sum algorithm for loopy graphs or can find exact solutions when the graph is a tree. LBP starts by initializing the beliefs of each agent about each of their possible states to zero. Each agent then passes a message containing a vector of belief values to each of its neighbors in the network. Once all agents have passed a message to each of their neighbors, each agent updates its beliefs based upon the content of the messages it received. The cycle of message passing and belief update continues until the network becomes stable when finally, the states of the variables are determined.

As LBP suffers of scalability issues in (Penya-Alba, 2012) the authors introduce the Reduced Binarized Loopy Belief Propagation algorithm (RB-LBP). RB-LBP is based on the max-sum algorithm and introduces binary variables in order to encode decoupled buy and sell decisions and a selection term and an equality term in order to assure coherent decisions between participants.

A belief propagation-based method, called PD-LBP, was proposed in (Kong et al., 2017) for task allocation in dynamic environments. It is composed of two phases: a pruning phase that aims at reducing the searched resource providers, and a decomposition phase that decomposes the initial network into several independent sub-networks on which is operated in parallel the belief propagation algorithm. Also PD-LBP approach overcomes the limitation of LBP where only the quotes of the participants are considered, by considering both a reserve price and a deadline for agreement to be accomplished.

A decentralized approach for allocating agents to tasks whose costs increase over time was proposed in (Parker et al., 2017) aiming to minimize the increase in task. Based on max-sum algorithm, the authors show how a distributed coordination algorithm, can be used for including costs of tasks that grow over time, enabling a wider range of problems to be solved. 


\section{Proposed mechanism for automating closed-loop supply chains}

The current work considers the problem of supply chain formation as a form of coordinated commercial interaction. The considered supply chain scenario represents a network of production and exchange relationships that spans multiple levels of production or task decomposition.

The entities are characterized in terms of their capabilities to perform tasks, and their interests in having tasks accomplished. A central feature in the considered scenario is hierarchical task decomposition: in order to perform a particular task, an agent may need to achieve some subtasks, which may be delegated to other entity. These may in turn have subtasks that may be delegated, forming a supply chain through a decomposition of task achievement. Constraints on the task assignment arise from the underling suppliers' network as exemplified in Figure 1.

The final product owner $X 1$ at the root of the supply chain can chose among $X 2, X 3, X 4$ and $X 8$ sub-assembly suppliers. The length of the four possible supply chains is different because there may be 1st tier suppliers that are able to produce the sub assembly without further task decomposition. At lower levels a certain subassembly supplier or a certain part supplier has the option of choosing among multiple possible descendant suppliers. For example $\mathrm{X} 3$ may chose $\mathrm{X} 6$ or $\mathrm{X} 11$ as his fabricated part supplier and X5 may choose between X7 and X12 as raw material suppliers.

Our work aims at providing support for linking end-consumer requirements to underlying suppliers to conjointly guarantee end-to-end agreed contract parameters and integrate the reverse supply chain by recycling and remanufacturing parts of the used good in order to exploit the opportunity for manufacturers. Due to the differences presented in Table 1, the contracts between partners in a closed-loop supply chain involve an increased complexity. For instance, in reverse supply chains the product quality is not uniform, the pricing is dependent on many factors and speed often is not considered a priority while in forward supply chains negotiation between parties is straightforward, in reverse supply chains the negotiation process is complicated by additional considerations.

In order to model the complexity of a closed-loop supply chain, the current work translates the Supply Chain Formation problem in terms of a directed acyclic graph where the nodes are represented by the agents. The entities involved in forward and reverse supply chain are heterogeneous and their payoffs obtained for being part of the supply chain are different and involve all kinds of different variables. These give raise to different utility values for a contract of the participating entities, according to their preferences and their specific interest in participating in the supply chain. 


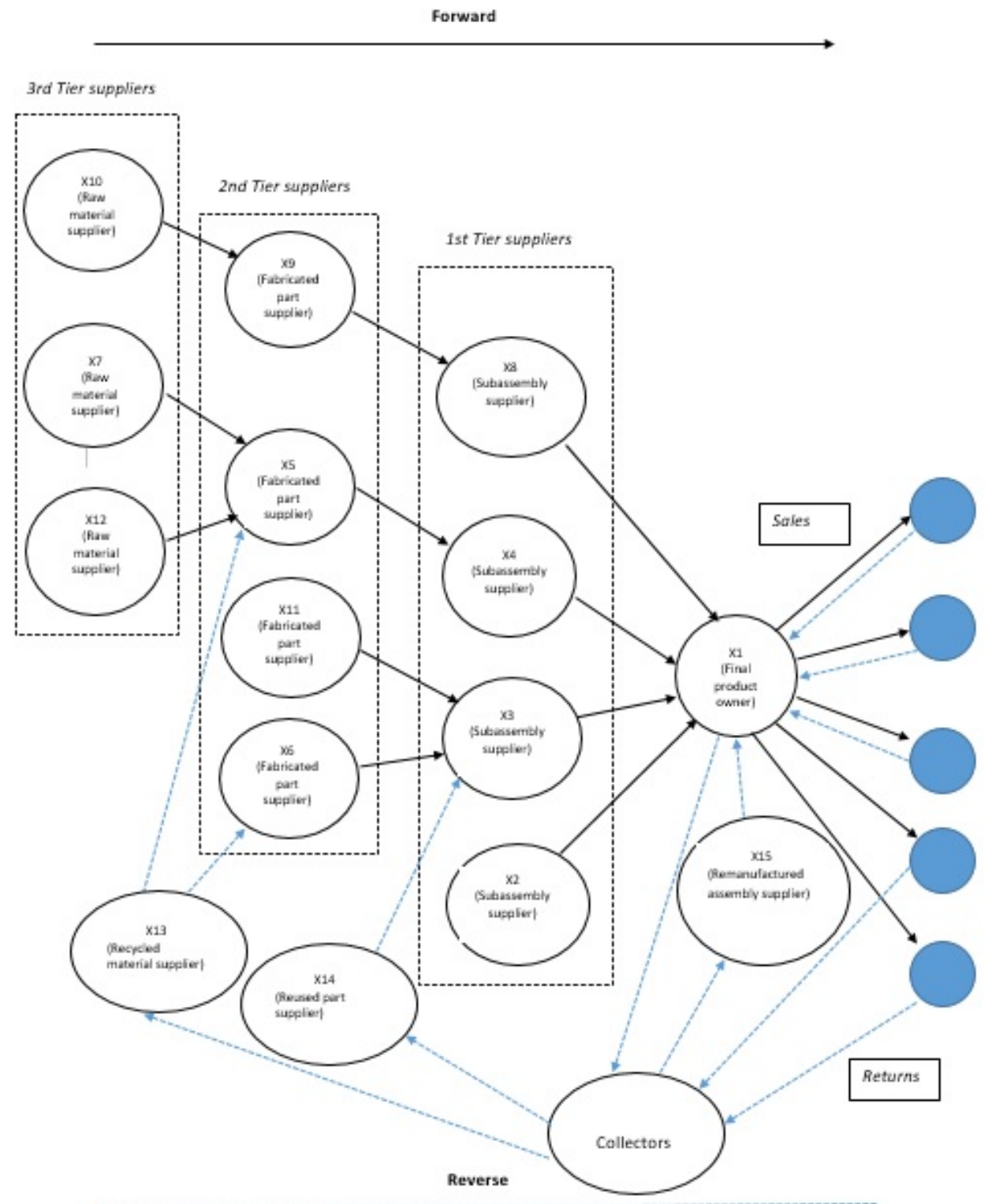

In the following we provide a formal description of the supply chain formation problem in terms of a directed, acyclic graph $(X, E)$ where $X=\left\{X_{1}, X_{2}, \ldots\right.$, $\left.X_{n}\right\}$ denote the set of participants in the supply chain represented by agents and a set of edges $\mathrm{E}$ connecting agents that might be involved in a form of commercial interaction. 
The agents need to agree on multiple contract parameters, the goal being to get a contract that is composed of the actual values of the issues that they have agreed on. Notation $U(v)$ represents the utility that a participant obtains from a contract. When a supplier (seller) negotiates with a consumer (buyer), both parties are interested in obtaining those contract values that maximize their utility functions $U(v)$. This means that during the negotiation, the agents send messages to their neighbors regarding the states of their variables that are maximizing their utility functions.

To solve the SCF problem we need to get an allocation, representing a sub-graph $\left(X^{\prime}, E^{\prime}\right) \subseteq(X, E)$. An edge $E$ between $X i, X_{j}$ means that agent $X j$ provides goods to agent $X_{i}$. An agent is in an allocation graph if it acquires or provides goods.

The agents communicate one to each other by sending messages according to their preferences over the parameters they share in their contracts. By sending the the max-marginalization of $B$ over $A\left(\max A\left(U\left(a_{i}, b_{j}\right)\right)\right.$ agent $X_{i}$ says to $X_{j}$ which is his preferred value from the set of values for issue $B$ that they share .

$$
\lambda_{i \rightarrow j}(B)=\max _{B}\left(U\left(b_{j}, c_{k}\right)+\max _{A}\left(U\left(a_{i}, b_{j}\right)\right)\right)
$$

$X_{j}$ assesses the received message and afterwards adds his own computed utility and finally computes the max marginalization of $B$ over the above terms, according to equation (1) and send it to the next participant in the supply chain.

The message passing process continues until it reaches the final product owner and afterwards the messages are sent back. For example, in Figure 1, the subassembly supplier X3 needs fabricated parts from fabricated part supplier X6 and also from reused parts supplier X14. Either the parts are new or reused the subassembly supplier needs them both in order to assembly an engine for example and to send it further to $\mathrm{X} 1$. Hence, $\mathrm{X} 3, \mathrm{X} 6$ and $\mathrm{X} 14$ need to agree on parameter time when they discuss about the contacts and afterwards $X 3$ needs to agree further with $X 1$ regarding the delivery time of the subassembly.

The above mechanism provides means for automating closed-loops supply chains described in the considered scenario, in the context of the digitalization process that Industry 4.0 imposes.

\section{Implementation and Evaluation}

To run the proposed mechanism described in the previous section and to analyze results, we need an implementation of the algorithm within an execution environment. Hence, we describe hereafter our practical implementation of the theoretical solution proposed in the section above.

Our implementation uses the factor graph (.fg) file format from libDAl (Mooij, 2010), which supplies an open source library for approximate inference in graphical models. We specifically use the .fg file format of libDAl, enhancing each factor of our model by specifying which variables occur in that factor, together with the number of possible values for the variable. We add a table listing all the values of that factor for all possible configurations of these variables. 
We have implemented the proposed algorithm on Apache Spark2 using the GraphX3 format for graphs and we have used Databricks Community Edition as a platform in order to run our experiments.

Figure 2. Closed-loop supply chain in the textile industry

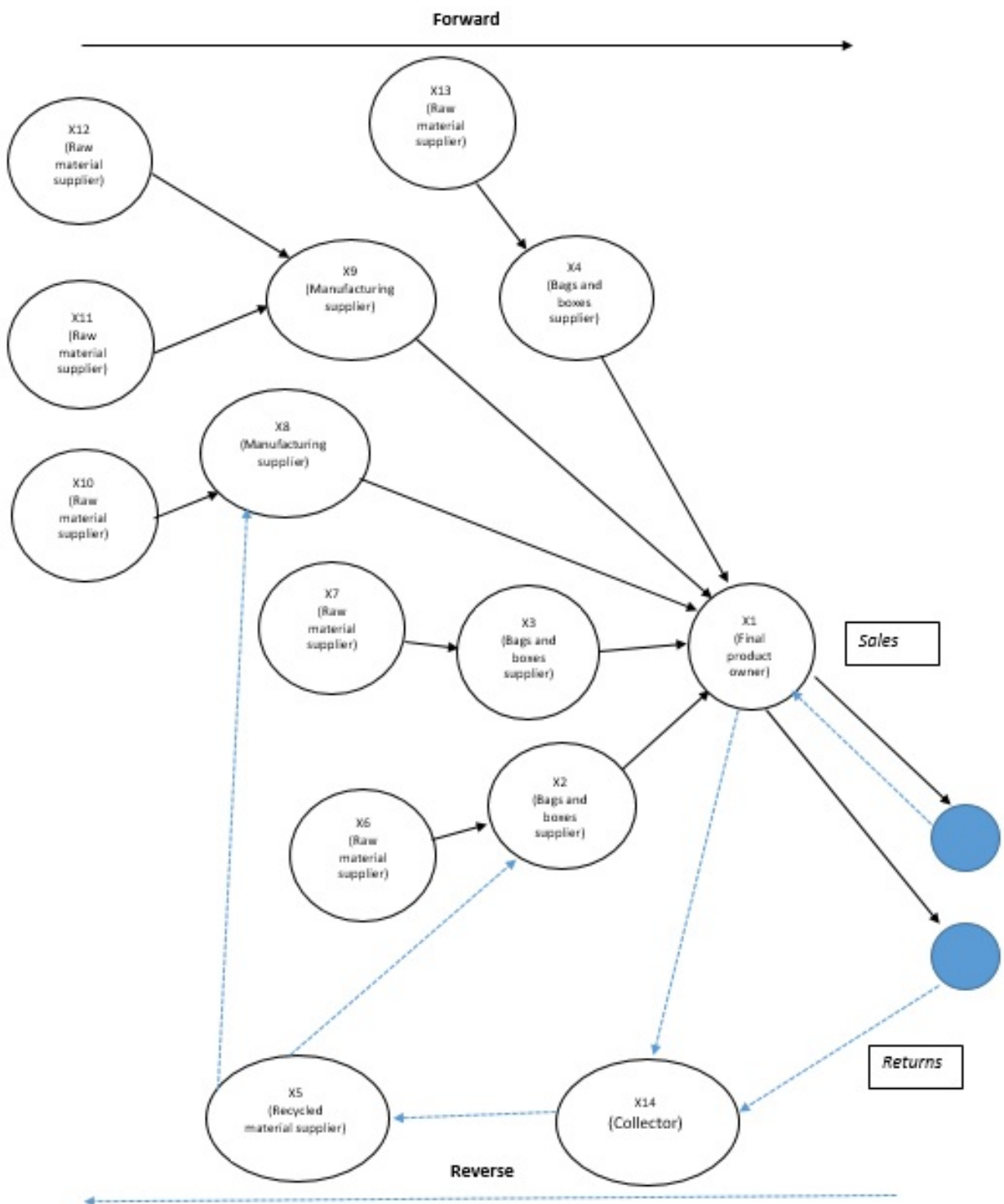

The experiments were run on two types of supply chain configurations from two different industries: the textile industry and automobile industry. The considered configurations of the supply chains are presented in Figure 2 and Figure 3. 
The big brands in the fashion industry collect nowadays used clothing in their stores worldwide. The clothes can be any condition or brand, and they are using the clothing they've collected to create all-recycled clothing lines or to create mixed fibers from new raw material and recycled fibers. The returns are extremely effective as the delivered returned goods can be re-launched into the supply chain: either in their current state or after appropriate modification.

Figure 3. Closed-loop supply chain from the automobile industry

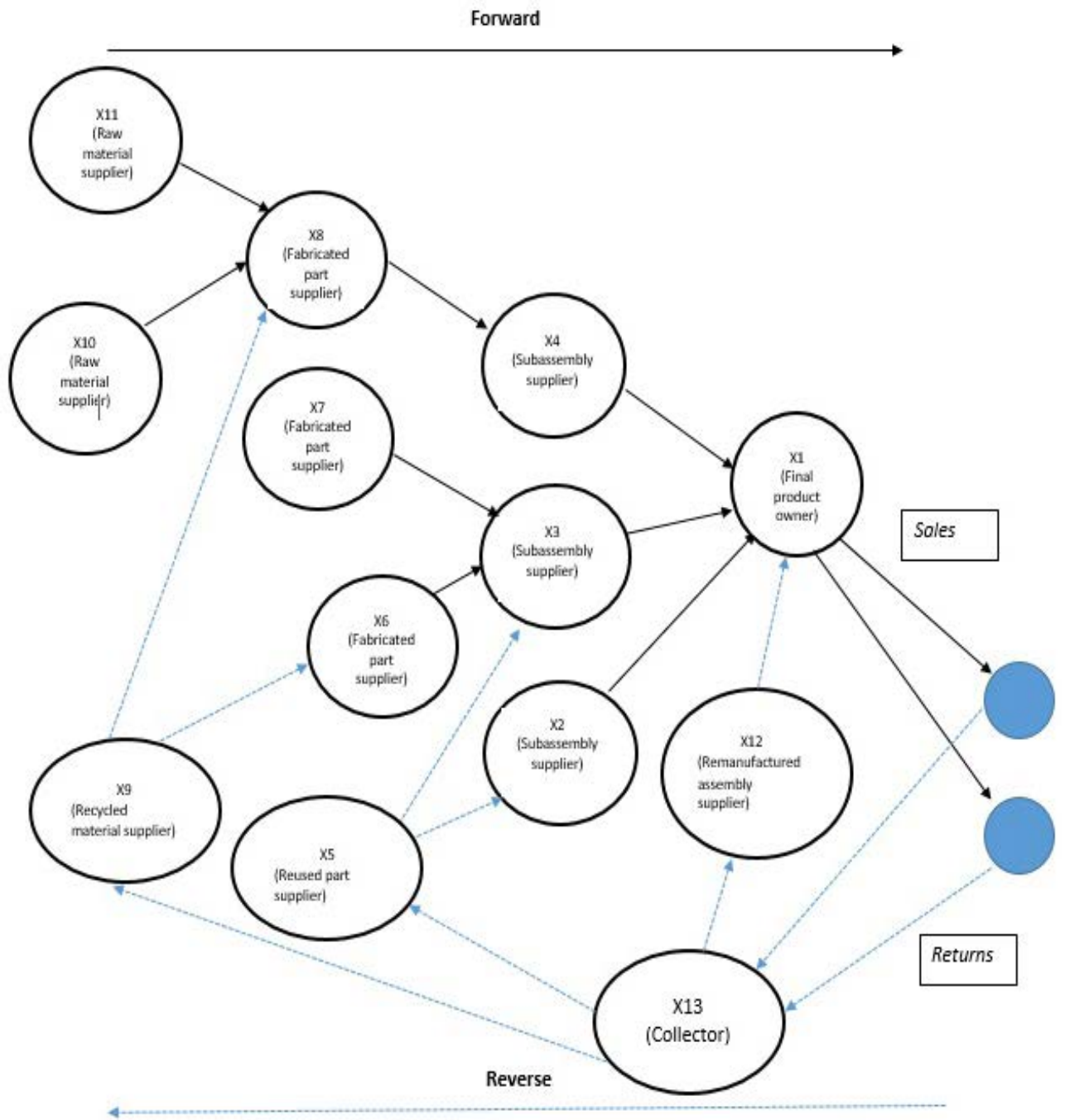

For the automobile industry, the importance of reverse logistics remains incontestable as it becomes dominant due to various reasons. The most important reasons to mention are the increasing product recalls, the changes within the 
legislative requirements, and focus over environmental issues. As the time passes, the increased requirement for recovering the returned vehicles is getting enhanced attention mainly owed to the recent environmental concerns. The primary areas that are recovered are parts in working order that are getting reused, assemblies such as engines, alternators, starters and transmissions that are remanufactured and materials that are recycled.

To estimate the impact and the benefits of implementing closed-loop supply chains we have run series of experiments in two stages: in the first stage we are using only forward supply chains and at the second stage we have run experiments using closed loop supply chains.

The utility functions assigned to every participant in the supply chain, involve two up to three parameters like price, time and quality. Every participant gives a certain weight for each parameter in his utility function in order to express his preference over the parameters. Hence, for each one of the two networks configuration considered, we randomly generated weights for the final product owner in order to obtain three categories of utility functions: "price-pref", "time-pref", "quality-pref". We have named the categories according to the most weighted parameter, in order to emphasize the preference over the considered parameters. Figures 4-9 emphasize the experiments results.

\section{Figure 4. Textile industry "price-pref" Figure 5. Textile industry "quality-pref"}
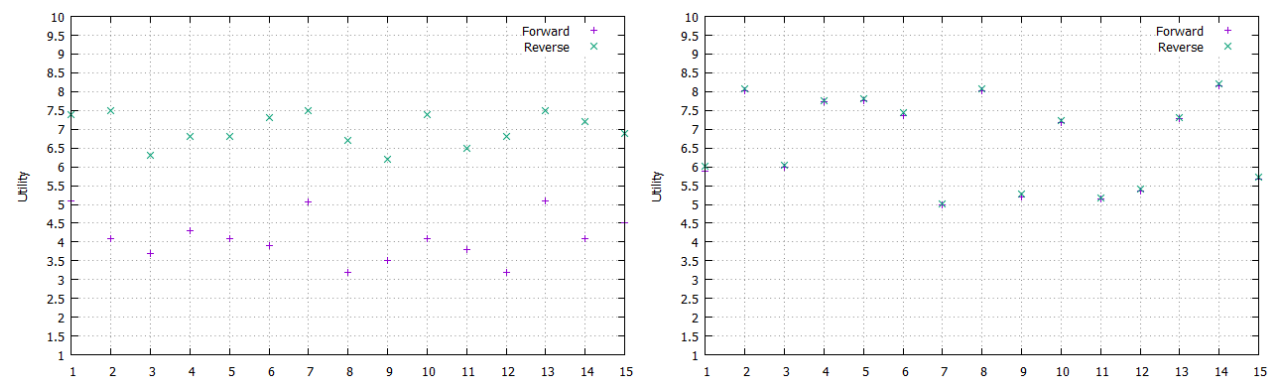

Figure 6. Textile industry "time-pref"

Figure 7. Auto industry "price-pref"
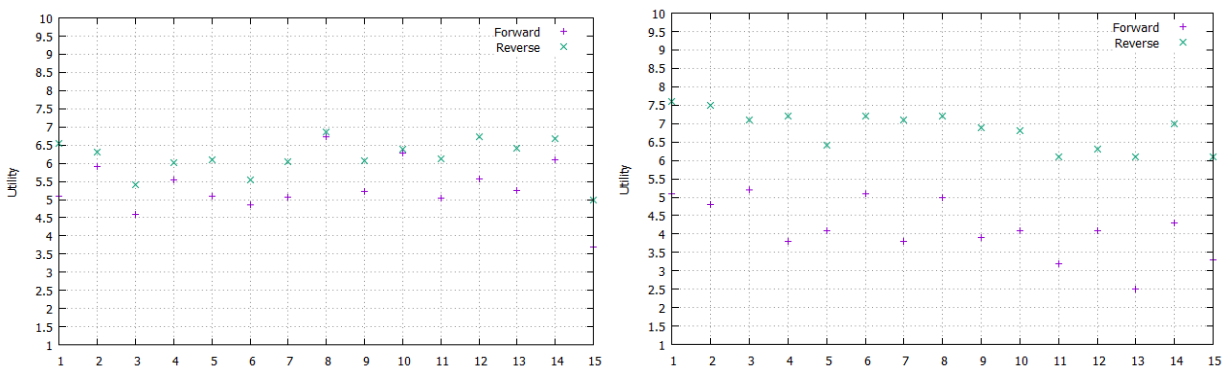
Figure 8. Auto industry "quality-pref"

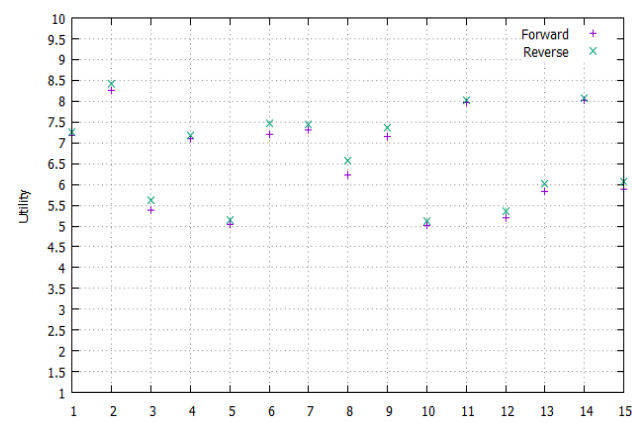

Figure 9. Auto industry "time-pref"

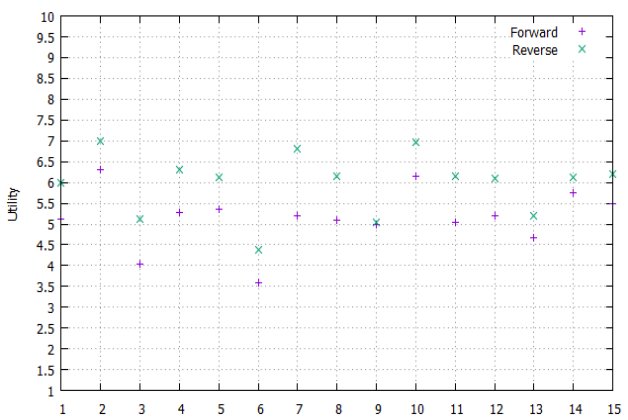

On the other side, Figure 5 and 8 show that when participants own "qualitypref" utility functions, integrating reverse supply chains doesn't bring much benefits over forward supply chains. This might be due to the fact that the final owner of the product cannot accept a lower quality for the products when using recycled raw materials or remanufactured assemblies. Figure 6 and 9 show that when time is the most important criteria, integrating reverse supply chains can bring certain advantages. Even the impact is not as high as when using "price-pref" utility functions, it stills brings a higher utility for the entities in the supply chain.

The forecasts regarding the recycled materials may be more difficult to estimate as there is no certain amount of returns when using reverse supply chains, therefore the entities in the supply chains might need to agree longer periods for delivering the required products.

It can be observed that the above presented trends are present in both considered industries: textile and automobile industry. Hence, we can say that integrating reverse supply chains along with forward supply chains can bring certain advantages to the final owner of the product, even though it might face several challenges in the integrating process like: no uniform product quality, difficult forecasting of the delivered quantities, longer negotiated periods for delivering products.

\section{Conclusions}

Initially, the growing attention on Reverse Supply Chains and Closed-Loop Supply Chain issues originated with public awareness. Then governmental legislation forced producers to take care of their end of life products. In other cases, companies are taking the initiative, seeing opportunities to reduce their operating costs by reusing products or components.

The current work proposed a mechanism that can automate the formation of supply chains in the in the context of Industry 4.0 using utility functions that can capture the increased complexity in closed-loop supply chains. Previous work regarding automating supply chains was focusing only on the forward supply chains, hence the proposed mechanisms advances the state of the art regarding supply chain formation by providing support to integrate the reverse supply chain by recycling and remanufacturing parts of the used good in order to exploit the opportunity for manufacturers. The integration of forward and reverse supply chains in a closed- 
loop supply chain involve an increased complexity of the contracts between the entities in the supply chain as in reverse supply chains the product quality is not uniform, the pricing is dependent on many factors and speed often is not considered a priority while in forward supply chains negotiation between parties is straightforward, in reverse supply chains the negotiation process is complicated by additional considerations.

However, the proposed mechanism may encounter efficiency issues when the contract parameters are taking values over continuous domains.

For further research, it is recommended to evaluate the impact of the integrating reverse supply chains along with forward supply chains, when incorporating more issues in the utility functions of the entities involved in the supply chain. Whether a company is using a closed loop supply chain by choice or necessity, it will face many challenges. It will have to educate customers and establish new points of contact with them, decide which activities to outsource and which to do itself, and in general figure out how to keep costs to a minimum while discovering innovative ways to recover value while meeting stringent environmental standards.

\section{References}

Aitken, J., Harrison, A. (2013). Supply governance structures for reverse logistics systems. International Journal of Operations \& Production Management, 33(6), 745-764.

Bishop, C. (2006). Pattern recognition and machine learning. New York: Springer.

Brettel, M., Friederichsen, N., Keller, M., Rosenberg, M., 2014. How Virtualization, Decentralization and Network Building Change the Man-Ufacturing Landscape: An Industry 4.0 Perspective. International Journal of Mechanical, Industrial Science and Engineering, Volume 8, 37-44.

Cerquides, J., Endriss, U., Giovannucci, . A., Rodriguez-Aguilar, J. A. (2007). Bidding languages and winner determination for mixed multi-unit combinatorial auctions. s.I., IJCAI, Morgan Kaufmann Publishers Inc..

Chan, F., Chan, H., Jain, V. (2012). A framework of reverse logistics for the automobile industry. International Journal of Production Research, 50(5), 13181331.

Collins, J., Ketter, W., Gini, M., Mobasher, B. (2002). A multi-agent negotiation testbed for contracting tasks with temporal and precedence constraints. International Journal of Electronic Commerce, Vol. 7.

Cooper, M., Lambert, D., Pagh, J. D. (1997). Supply chain management: more than a new name for logistics. The International Journal of Logistics Management, 8(1), 1-9.

Demirel, E., Demirel, N., Gökçen , H. (2014). A mixed integer linear programming model to optimize reverse logistics activities of end-of-life vehicles in Turkey. Journal of Cleaner Production.

Fleischmann, M. (2001). Quantitative Models for Reverse Logistics. In: Lecture Notes in Economics and Mathematical Systems., p. 501.

Geissbauer, R., Vedsø, J., Schrauf, S. (2016). A Strategist's Guide to Industry 4.0: Global businesses are about to integrate their operations into a seamless digital whole, and thereby change the world.. Strategy and Business. 
Giovannucci, A., Cerquides, J., Rodríguez-Aguilar, J. (2010). Composing supply chains through multiunit combinatorial reverse auctions with transformability relationships among goods. IEEE Transactions on Systems, Man, and Cybernetics - Part A: Systems and Humans, 40(4), 767-778.

Giovannucci, A., Vinyals, M., Rodriguez-Aguilar, J., Cerquides, J. (2008). Computationally-efficient winner determination for mixed multi-unit combinatorial auctions. S.l., Proceedings of the 7th international joint conference on Autonomous agents and multiagent systems, Vol. 2, 1071-1078.

Govindan, K., Soleimani, H., Kannan, D. (2015). Reverse logistics and closed-loop supply chain: A comprehensive review to explore the future, European Journal of Operational Research, Volume 240, Issue 3, 603-626

Grabara, J., Man, M., Kolcun, M. (2014). The benefits of reverse logistics. International Letters of Social and Humanistic Sciences, Vol. 15, 138-147.

Guide, V., Van Wassenhove, L. (2009). The evolution of closed-loop supply chain research. Operations Research, 57(1), 10-18.

Hahn, T. (2014). Future of Manufacturing - View on enabling technologies, s.I.: Siemens Corporate Technology.

Khan, S. A. R., Qianli, D., SongBo, W., Zaman, K., 2017. Environmental logistics performance indicators affecting per capita income and sectoral growth: evidence from a panel of selected global ranked logistics countries. Environmental Science and Pollution Research, 24(2), 1518-1531.

Khan, S. A. R., Zaman, K., Zhang, Y. (2016). The relationship between energyresource depletion, climate change, health resources and the environmental Kuznets curve: Evidence from the panel of selected developed countries. Renewable and Sustainable Energy Review, Vol. 62, 468-477.

Kong, Y., Zhang M., Ye, D. (2017) A Belief Propagation-based Method for Task Allocation in Open and Dynamic Cloud Environments, Knowledge-Based Systems, vol. 115, 123-132.

Melo, M., Nickel, S., Saldanha-da-Gama, F. (2009). Facility location and supply chain management - A review. European Journal of Operational Research, 196(2), 401-412.

Mikhaylov, B., Cerquides, J., Rodriguez-Aguilar, J. (2011). Solving sequential mixed auctions with integer programming. Advances in Artificial Intelligence, Springer, 42-53.

Mooij, J. M. (2010). libDAl: A free and open source c++ library for discrete approximate inference in graphical models. Journal of Machine Learning Research, Volume 11, 2169-2173.

Parker, J., Farinelli A., Gini, M. (2017). Max-Sum for Allocation of Changing Cost Tasks, Intelligent Autonomous System. Advances in Intelligent Systems and Computing, vol. 531, 629-642.

Patroklos, P., Besoiu, M., 2010. Environmental and economical sustainability of WEEE closed-loop supply chains with recycling: a system dynamics analysis. The International Journal of Advanced Manufacturing Technology, 47(5-8), 475-493.

Penya-Alba, T., Vinyals, M., Cerquides, J., Rodriguez-Aquilar, J. (2012). A scalable Message-Passing Algorithm for Supply Chain Formation. s.l., 26th Conference on Artificial Intelligence. 
Quariguasi Frota Neto, J., Walther, G., Bloemhof, J., van Nunen, J.A.E.E., Spengler, T. (2010). From closed-loop to sustainable supply chains:The WEEE case. International Journal of Production Research, 48(15), 4463-4481.

Ravi, V., Shankar, R. (2012). Evaluating alternatives in reverse logistics for automobile organisations. International, 12(1), 32-51.

Rubio, S., Parra, B. (2014). Reverse Logistics: Overview and Challenges for Supply Chain Management. International Journal of Engineering Business Management, vol. 6.

Snyder, L. V. (2006). Facility location under uncertainty: A review. IIE Transactions, 38(7), 537-554.

Tibben-Lembke, R., Rogers, D. (2002). Differences between forward and reverse logistics in a retail environment. Supply Chain Management: An International Journal, 7(5), 271-282.

Walsh , W. E., Wellman, M. P., Ygge, F. (2000). Combinatorial auctions for supply chain formation, Proceedings of the 2nd ACM conference on Electronic commerce.

Walsh, W., Wellman, M. P. (2003). Decentralized supply chain formation: A market protocol and competitive equilibrium analysis. Journal of Artificail Intelligence Research, Volume 19, 513-567.

Winsper, M., Chli, M. (2013). Decentralized supply chain formation using max-sum loopy belief propagation. Computational Intelligence, 29(2), 281-309.

Winsper, M., Chli, M. (2010). Decentralised supply chain formation: A belief propagation-based approach. Agent-Mediated Electronic Commerce.

Winsper, M., Chli, M. (2012). Using the max-sum algorithm for supply chain formation in dynamic multi-unit environments. s.l.: Proceedings of the 11th International Conference on Autonomous Agents and Multiagent Systems. 